\title{
Relaxation of Rabbit Corpus Cavernosum Smooth Muscle and Aortic Vascular Endothelium Induced by New Nitric Oxide Donor Substances of the Nitrosyl-Ruthenium Complex
}

\author{
Joao B. G. Cerqueira, Lucio F. G. Silva, Luis G. F. Lopes, Maria E. A. Moraes, Nilberto R. F. \\ Nascimento
}

Division of Urology (JBGC, LFGS), Department of Chemistry (LGFL), Department of Pharmacology and Physiology (MEAM) and Institute of Biomedical Sciences (NRFN), Federal University of Ceara, Fortaleza, CE, Brazil

\begin{abstract}
Introduction: Endothelial dysfunction characterized by endogenous nitric oxide (NO) deficiency made $56 \%$ of patients affected with erectile dysfunction decline treatment with PDE-5 inhibitors. New forms of treatment are currently being developed for this group of patients.

Materials and Methods: The study compared the effect of sodium nitroprusside (SNP) and two substances of the nitrosyl-

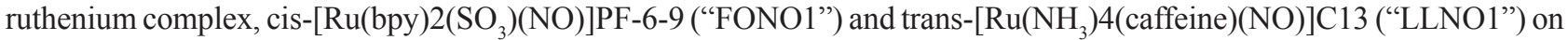
relaxation of rabbit corpus cavernosum smooth muscle and aortic vascular endothelium. The samples were immersed in isolated baths and precontracted with $0.1 \mu \mathrm{M}$ phenylephrine $(\mathrm{PE})$ and the corresponding relaxation concentration/response curves were plotted. In order to investigate the relaxation mechanisms involved, $100 \mu \mathrm{M}$ ODQ (a soluble guanylate cyclase-specific inhibitor), $3 \mu \mathrm{M}$ or $10 \mu \mathrm{M}$ oxyhemoglobin (an extracellular NO scavenger) or $1 \mathrm{mM}$ L-cysteine (a nitrosyl anion-specific scavenger) was added to the samples.

Results: All the NO donors tested produced a significant level of relaxation in the vascular endothelium. In corpus cavernosum samples, FONO1 produced no significant effect, but LLNO1 and SNP induced dose-dependent relaxation with comparable potency $\left(\mathrm{pEC}_{50}=6.14 \pm 0.08\right.$ and $6.4 \pm 0.14$, respectively) and maximum effect (Emax $=82 \%$ vs. $100 \%$, respectively). All NO donors were found to activate soluble guanylate cyclase, since the addition of the corresponding inhibitor $(100 \mu \mathrm{M}$ ODQ) completely neutralized the relaxation effect observed. The addition of oxyhemoglobin reduced the relaxation effect, but did not inhibit it completely. In aortic vascular endothelium $3 \mu \mathrm{M}$ oxyhemoglobin decreased the relaxation effect by $26 \%$ on the average, while $10 \mu \mathrm{M}$ oxyhemoglobin reduced it by over $52 \%$. The addition of $100 \mu \mathrm{M}$ L-cysteine produced no significant inhibiting effect.

Conclusions: These results suggest that LLNO1 and FONO1 are potent vasodilators. LLNO1 was shown to induce a significant level of relaxation in rabbit corpus cavernosum. The substances tested were shown to activate soluble guanylate cyclase and release intracellular NO.
\end{abstract}

Key words: nitric oxide; vascular endothelium; corpus cavernosum; nitrosil-ruthenium complex Int Braz J Urol. 2008; 34: 638-46

\section{INTRODUCTION}

The vascular smooth muscles of the human corpus cavernosum are contracted tonically by adrenergic stimulation to maintain the penis flaccid (1).
Conversely, penile erection occurs when the corpus cavernosum smooth musculature is relaxed by the activation of inhibitory nerve endings and the decrease in adrenergic stimulation. 
Nitric oxide was shown to be the neurotransmitter released from the "non-adrenergic-non-cholinergic" nervous fibers that elicited corpora cavernosa relaxation and penile erection (2). Nitric oxide (NO) is the main inhibitory neurotransmitter in animal and human corpus cavernosum mediating penile erection (1). It was primarily the work of Palmer and Moncada that led to the discovery of NO as an endothelium-derived relaxing factor (3). NO activates soluble guanylate cyclase, which in turn induces cyclic guanosine monophosphate (cGMP) production from guanosine triphosphate. cGMP acts on intracellular effectors, such as protein kinase $\mathrm{G}$, which reduce intracellular calcium levels and dissociate actin and myosin fibers, leading to smooth muscle relaxation (4).

NO donors are substances releasing NO in vivo or in vitro. The NO donor sodium nitroprusside (SNP) is a powerful vasodilator used clinically to treat acute hypertension. However, the substance is very unstable and may induce drug tolerance and release not only NO but also cyanide, which is toxic for the vascular endothelium (5).

Several more stable and less toxic NO donors have been tested over the past years. Some of these, S-nitrosoglutathione (GSNO) and S-nitroso-N-acetylcysteina-ethylester, have been used in studies with human corpus cavernosum strips mounted in isolated tissue baths with a promising potential for tissue relaxation (6).

Likewise, NO donors with ruthenium metal center have recently been the object of attention. These substances, which were initially used on rat hippocampus in vitro, have a potentializing effect shown to be reversible by pretreating tissues with oxyhemoglobin, an extracellular NO scavenger (7). Because the ruthenium metal center controls the levels of circulating NO by modulating the reduction potential of the latter, it can reduce the side effects of NO donors such as SNP in the clinical setting (8). In experiments using rat aortic vascular endothelium in vitro, substances of the nitrosyl-ruthenium complex produced a relaxation effect similar to that of SNP (9).

The objective of the present study was to compare the effect of SNP and of two substances of the nitrosyl-ruthenium complex, cis$\left[\mathrm{Ru}(\mathrm{bpy}) 2\left(\mathrm{SO}_{3}\right)(\mathrm{NO})\right] \mathrm{PF}-6-9$ (henceforth termed
FONO1) and trans-[Ru( $\left.\mathrm{NH}_{3}\right) 4($ caffeine $\left.)(\mathrm{NO})\right] \mathrm{C} 13$ (henceforth termed LLNO1) upon the relaxation of rabbit corpus cavernosum smooth muscle and aortic vascular endothelium.

\section{MATERIALS AND METHODS}

The study was approved by the Ethics Committee for Animal Research of the Federal University of Ceara. Tissue samples were obtained from adult male New Zealand rabbits weighing 2-3 Kg. After anesthetizing the animal, the penis was excised and immediately immersed in Krebs-Henseleit solution. Following sternotomy and excision of the heart, the thoracic aorta was dissected, removed and sectioned into circular fragments, which were immediately immersed in Krebs-Henseleit solution.

The corpus cavernosum tissue was dissected following removal of the connective tissues of the tunica albuginea, with each penis providing two segments of corpus cavernosum $(1 \mathrm{~cm}$ x $0.3 \mathrm{~cm}$ x 0.2 $\mathrm{cm})$. The samples were mounted in isolated tissue baths containing $10 \mathrm{~mL}$ Krebs-Henseleit solution $\left(37^{\circ} \mathrm{C} ; \mathrm{pH} 7.4\right)$ bubbled with carbogen $\left(95: 5 \mathrm{O}_{2} / \mathrm{CO}_{2}\right)$. The samples were mounted in the bath between two L-shaped electrodes, one of which was connected to an isometric force transducer and the other to a mobile rack for resting tension adjustment. All samples were subjected to $1 \mathrm{~g}$ tension.

The samples were monitored for 60 minutes with resting tension adjustment and solution change at 15-minute intervals. Variations in tension were measured with isometric transducers and registered with a polygraph (Gemini 7070, Ugo-Basile, Varese, Italy).

Following the 60 -minute resting period, the tissues were precontracted with $0.1 \mu \mathrm{M}$ phenylephrine (PE) and relaxation concentration/response curves were plotted.

\section{Methodology}

Experiment 1: Following precontraction with $1 \mu \mathrm{M}$ PE, graded concentrations $\left(10^{-12}\right.$ to $\left.10^{-3} \mathrm{M}\right)$ of SNP, FONO1 or LLNO1 were added to the baths and relaxation concentration/response curves were plotted. 
Experiment 2: $10 \mu \mathrm{M}$ oxyhemoglobin was added to the baths 30 minutes before precontraction with $1 \mu \mathrm{M}$ PE to evaluate the associated NO release rates. Relaxation concentration/response curves were plotted as in the previous experiment.

Experiment 3: To determine whether the substances tested released the $\mathrm{NO}^{-}$scavenger nitrosyl during relaxation, $100 \mu \mathrm{M}$ L-cysteine (L-cyst) was added to the baths 30 minutes before precontraction with $1 \mu \mathrm{M}$ PE. Relaxation concentration/response curves were plotted as in the previous experiment.

Experiment 4: To evaluate cGMP production induced by the test substances, $100 \mu \mathrm{M}$ soluble guanylate cyclase-specific inhibitor was added to the baths 30 minutes before precontraction with $1 \mu \mathrm{M}$ PE. Relaxation concentration/response curves were plotted as in the previous experiment.

\section{Statistical Analysis}

The relaxation effect corresponded to the plateau of phenylephrine contraction and was expressed as a percentage reversal. The maximum effect (Emax) was considered as the maximum amplitude response observed in the concentration-effect curve for each agent. The concentration required to produce half the maximum relaxation amplitude $\left(\mathrm{EC}_{50}\right)$ was determined after log transformation of the normalized concentration-response curves and expressed as negative logarithms $\left(\mathrm{pEC}_{50}\right)$ of the mean values for each tissue $(n=9)$. The statistical analyses were performed with the software GraphPad Prism 3.0 (Graph Pad Software Corporation, San Diego, CA.). Findings were expressed as average \pm standard error (SE). In each group of experiments $n$ indicates the number of samples analyzed. The statistical significance of differences between average values was determined with one-way variance analysis (ANOVA), followed by the Tukey-Kramer test. The level of statistical significance was set at $\mathrm{p}<0.05$.

\section{RESULTS}

\section{Evaluation of Relaxation Induced by Test Sub- stances}

Precontraction with $1 \mu \mathrm{M}$ PE produced a $100 \%$ increase in basal tension $(1 \mathrm{~g}-2 \mathrm{~g})$ in rabbit cor- pus cavernosum (RbCC). The maximum relaxation (Emax) and maximum potency $\left(\mathrm{pEC}_{50}\right)$ produced by SNP was $109.7 \%(p<0.05)$ and $6.4 \pm 0.14$, respectively. FONO1 induced little relaxation in RbCC samples (Emax: 31.2\%). LLNO1 induced relaxation with potency and maximum effect similar to SNP (Emax: $\left.81 \% ; \mathrm{pEC}_{50}: 6.14 \pm 0.08\right)(\mathrm{p}<0.05)($ Figure-1).

In aortic rings SNP yielded an Emax value of $112.4 \%$ and $\mathrm{pEC}_{50}$ value of $7.8 \pm 0.10(\mathrm{p}<0.05)$. The corresponding values were $149.8 \%$ and $7.5 \pm 0.38$ for FONO1 and $112.8 \%$ and $7.02 \pm 0.10$ for LLNO1 $(\mathrm{p}<0.05)$ (Figure-2).

\section{Effect of Soluble Guanylate Cyclase-Specific Inhibitor on Tissue Relaxation Induced By Test Substances}

Incubation of tissues with $100 \mu \mathrm{M}$ soluble guanylate cyclase-specific inhibitor (ODQ) completely neutralized the tissue relaxation effect of the three substances tested (data not shown).

\section{Effect of L-Cysteine on Relaxation Induced by Test Substances}

Incubation with $100 \mu \mathrm{M}$ of the $\mathrm{NO}^{-}$scavenger L-cysteine produced no significant change in the tissue relaxation effect of the three substances tested. Emax and $\mathrm{pEC}_{50}$ remained unchanged for both corpus cavernosum strips and aortic rings (Figure-3).

\section{Effect of Oxyhemoglobin on Tissue Relaxation Induced by LLNO1 and FONO1}

Incubation with $3 \mu \mathrm{M}$ of the extracellular NO scavenger oxyhemoglobin reduced, though not significantly, the relaxation power of the substances tested. Emax and $\mathrm{pEC}_{50}$ values were greater in aortic rings than in RbCC treated with LLNO1. However, when adding $10 \mu \mathrm{M}$ oxyhemoglobin, LLNO1 and FONO1-induced tissue relaxation decreased significantly with regard to both Emax and $\mathrm{pEC}_{50}$.

In samples treated with LLNO1, with the addition of $3 \mu \mathrm{M}$ oxyhemoglobin Emax and $\mathrm{pEC}_{50}$ values decreased less for RbCC than for aortic vascular endothelium. The maximum effect of LLNO1 in RbCC decreased from $80 \%$ to $63.98 \%$ (Figure-4).

In samples of aortic rings treated with LLNO1, $3 \mu \mathrm{M}$ oxyhemoglobin reduced maximum tissue relaxation from $112 \%$ to $48 \%$. At $10 \mu \mathrm{M}$ oxy- 


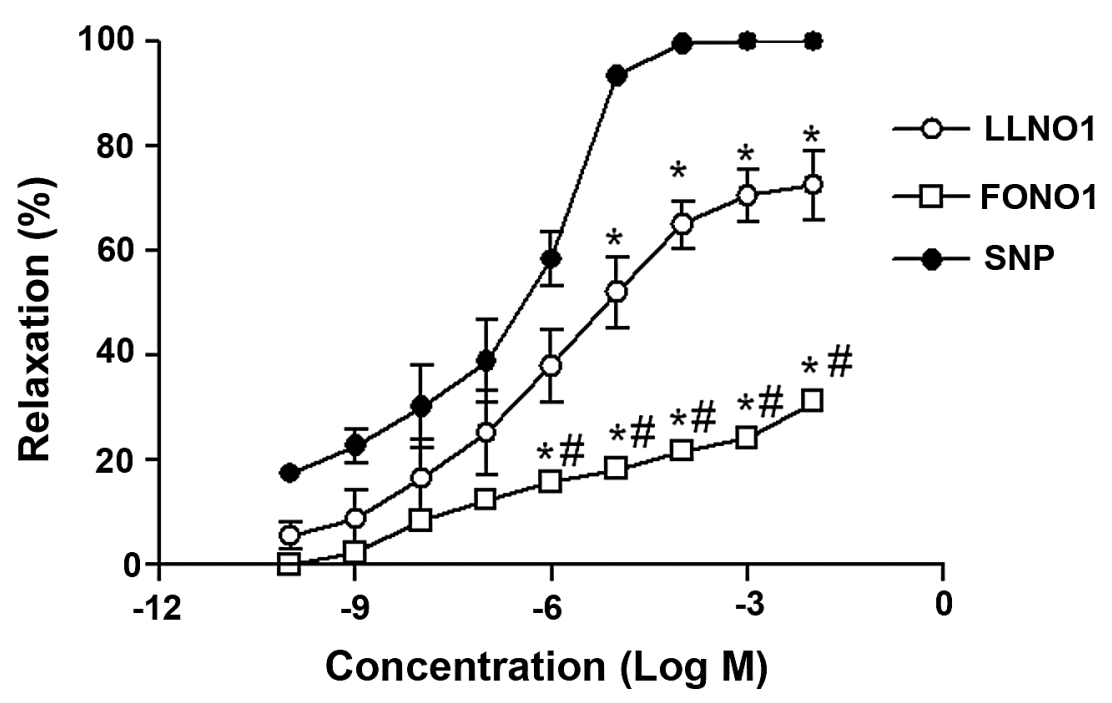

Figure 1 - Effect of LLNO1, FONO1 and sodium nitroprusside (SNP) upon rabbit corpus cavernosum (RbCC) strips. The RbCC strips were precontracted with $1 \mu \mathrm{M}$ phenylephrine and relaxation concentration/response curves (concentrations graded from $10^{-12}$ to $10^{-3}$ M) were plotted. Findings are expressed as average \pm standard error, based on six experiments. * $p<0.05$ vS. SNP (ANOVA followed by the Tukey-Kramer test). \# $p<0.05$ vs. LLNO1 (ANOVA followed by the Tukey-Kramer test).

hemoglobin, the $\mathrm{pEC}_{50}$ value changed from $7.02 \pm$ 0.10 to $6.9 \pm 0.23$ and the Emax value was further reduced to $38 \%(\mathrm{p}<0.05)$ (Figure-5).

In samples of aortic rings treated with FONO1, $3 \mu \mathrm{M}$ oxyhemoglobin significantly reduced Emax and
$\mathrm{pEC}_{50}$ values in relation to control samples $(42.74 \%$ vs. $150 \%$ and $6.9 \pm 0.23$ vs. $7.5 \pm 0.38$, respectively; $\mathrm{p}<0.05$ ) (Figure-5). At $10 \mu \mathrm{M}$ oxyhemoglobin, the Emax value was further reduced from $42.74 \%$ to $26 \%$ $(\mathrm{p}<0.05)$ (Figure-5).

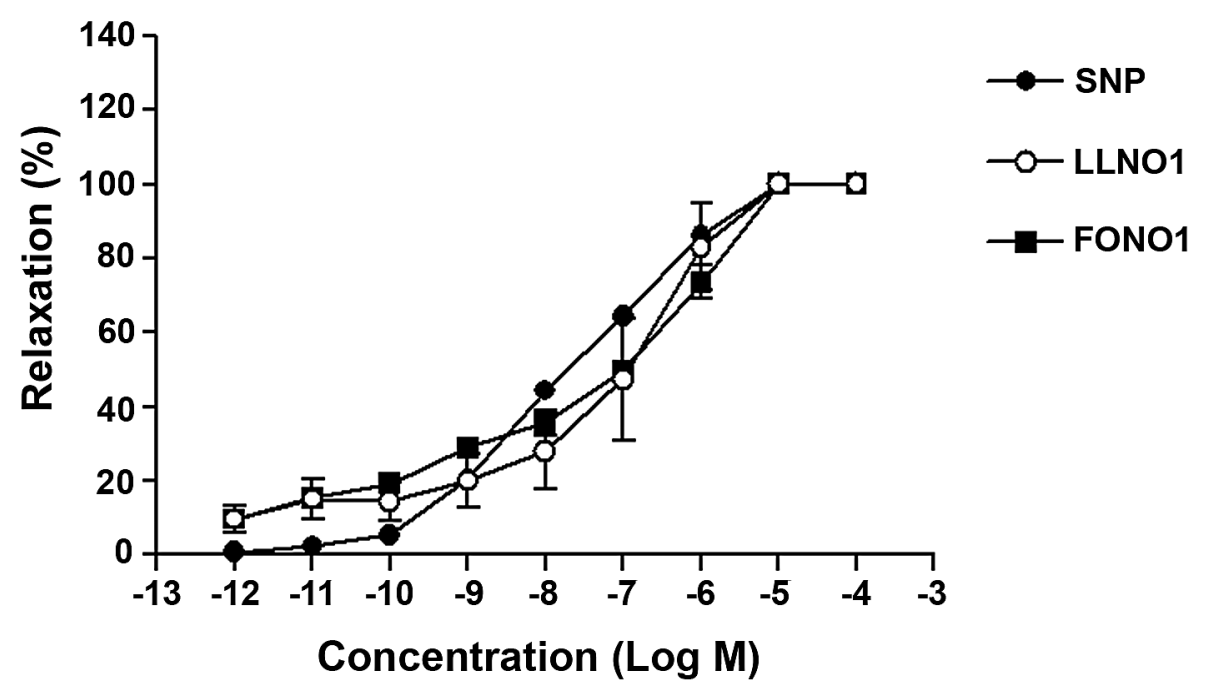

Figure 2 - Effect of LLNO1 upon aortic vascular endothelium rings. The rings were precontracted with $1 \mu M$ phenylephrine and relaxation concentration/response curves (concentrations graded from $10^{-12}$ to $10^{-3} \mathrm{M}$ ) were plotted for LLNO1 and compared with sodium nitroprusside curves. Findings are expressed as average \pm standard error, based on six experiments. 


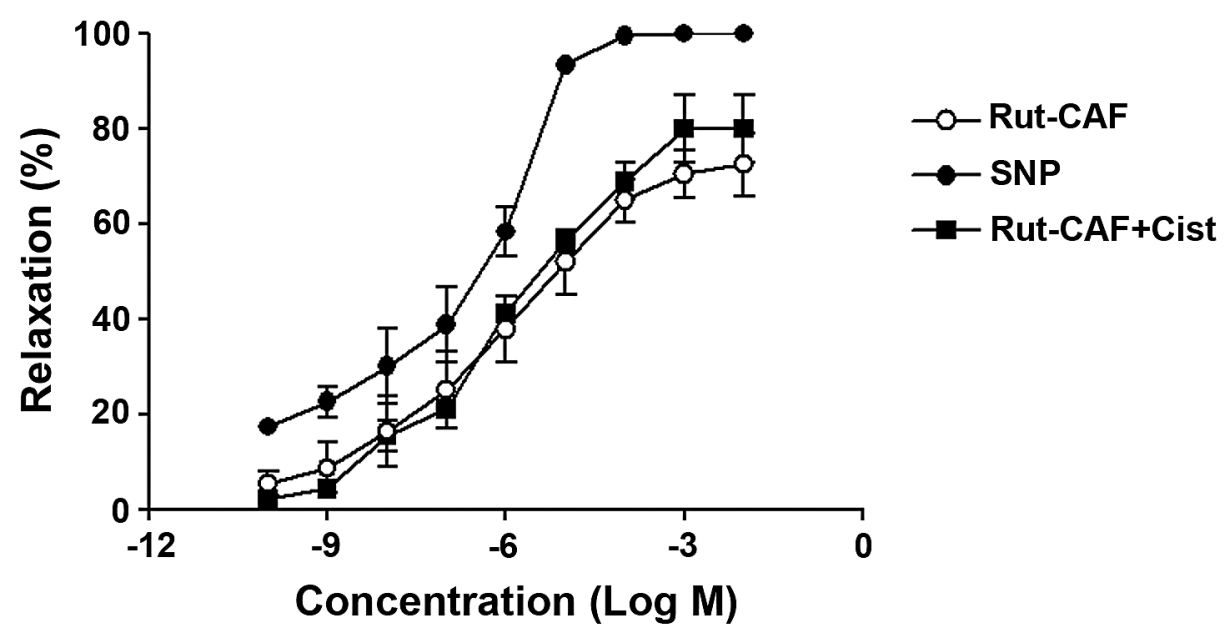

Figure 3-Effect of LLNOI alone and in combination with L-Cysteine (L-Cyst) upon rabbit aortic rings. The rings were precontracted with $1 \mu \mathrm{M}$ phenylephrine and relaxation concentration/response curves (concentrations graded from $10^{-12}$ to $10^{-3} \mathrm{M}$ ) were plotted for LLNO1 alone and in combination with $100 \mu M$ L-Cyst. Findings are expressed as average \pm standard error, based on six experiments. p > 0.05 vs. LLNO1 + L-cyst, SNP, LLNO1 (ANOVA followed by the Tukey-Kramer test).

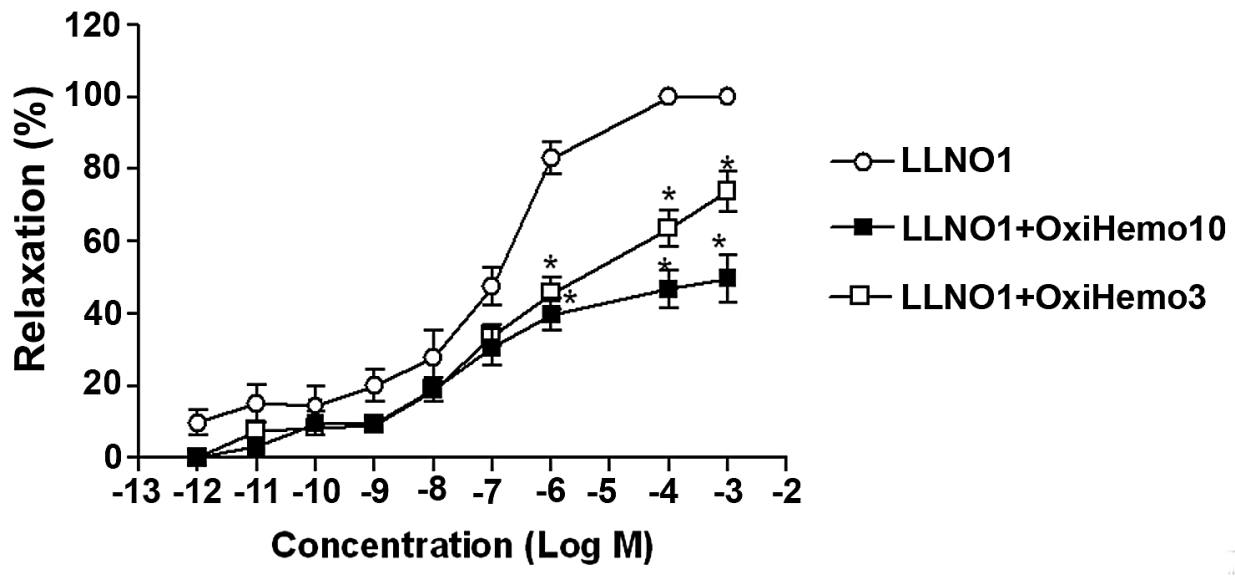

Figure 4-Effect of LLNO1 alone and in combination with oxyhemoglobin upon rabbit corpus cavernosum strips. The RbCC strips were precontracted with $1 \mu \mathrm{M}$ phenylephrine and relaxation concentration/response curves (concentrations graded from $10^{-12}$ to $10^{-3} \mathrm{M}$ ) were plotted for LLNO1 alone and in combination with $3 \mu M$ or $10 \mu M$ oxyhemoglobin. Findings are expressed as average \pm standard error, based on six experiments. $* p<0.05$ vs. LLNO1 + oxyhemoglobin (ANOVA followed by the Tukey-Kramer test).

\section{COMMENT}

Endothelial dysfunction is observed in many patients with erectile dysfunction or comorbidities such as arterial hypertension and diabetes (10). The syndrome is characterized by a deficiency in the endogenous production of nitric oxide (11). Since approximately $56 \%$ of subjects affected with erectile dysfunction decline treatment with the commercially available PDE-5 inhibitors (11), new drugs capable of increasing the availability of endogenous NO are being tested. The present study tested the ability of two 


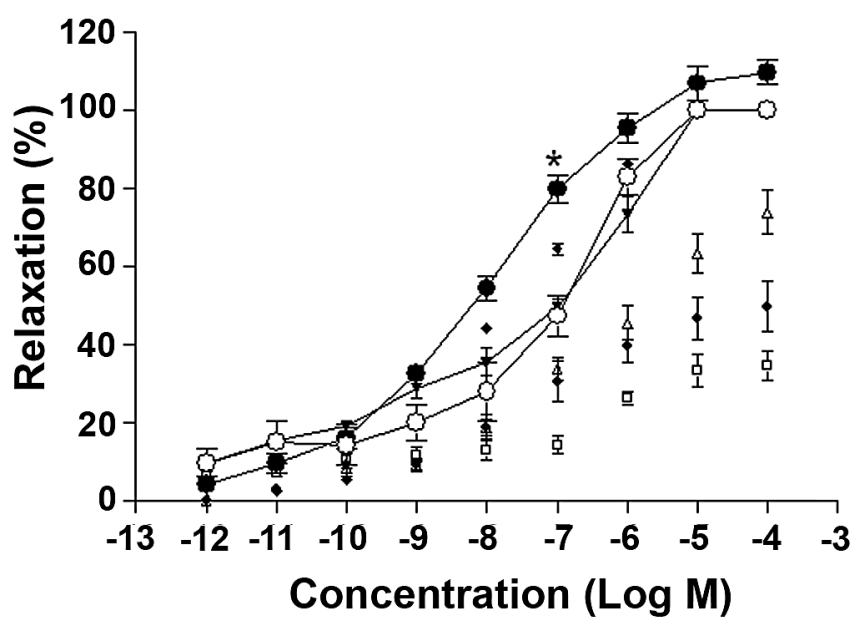

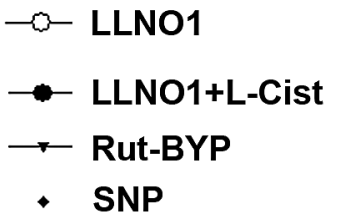

- Rut-CAF+OxyHemo10

- Rut-BYP+OxyHemo10

$\triangle$ Rut-CAF+OxyHemo3

Figure 5-Effect of LLNO1 and FONO1 alone and in combination with oxyhemoglobin or L-cysteine upon aortic vascular endothelium rings. The rings were precontracted with $1 \mu M$ phenylephrine and relaxation concentration/response curves (concentrations graded from $10^{-12}$ to $10^{-3} \mathrm{M}$ ) were plotted for LLNO1 and FONO1 alone and in combination with $100 \mu \mathrm{ML}$-Cyst or $3 \mu \mathrm{M}$ or $10 \mu \mathrm{M}$ oxyhemoglobin. Findings are expressed as average \pm standard error, based on six experiments. $* p<0.05 v s$. LLNO1 $+3 \mu M$ or $10 \mu M$ oxyhemoglobin. FONO1 + $10 \mu$ M oxyhemoglobin (ANOVA followed by the Tukey-Kramer test).

new substances of the nitrosyl-ruthenium complex to promote relaxation in rabbit corpus cavernosum smooth musculature and aortic vascular endothelium.

The fact that FONO1 and LLNO1 produced a larger maximum relaxation effect (Emax) in aortic vascular rings than $\mathrm{SNP}$, with potencies $\left(\mathrm{pEC}_{50}\right)$ similar to SNP, shows that substances of this group are associated with greater endogenous NO availability than SNP. Similar results were published by Bonaventura and colleagues (9) in a study evaluating substances of the nitrosyl-ruthenium complex. In that study, one of the substances tested achieved a maximum effect of $102 \%$ and $\mathrm{pEC}_{50}$ of $6.61 \pm 0.09$, thus supporting the present findings that substances of the nitrosylruthenium complex can be potent vasodilators.

In this study, FONO1 failed to induce significant levels of relaxation in corpus cavernosum samples. The performance of LLNO1 was similar to that of SNP, though Emax values were lower than for vascular endothelium samples. This may be explained by the different mechanisms displayed by NO donors in vessels of different sizes. As demonstrated by Sathishkumar et al. (12), while NO donors of the thiol group, such as S-nitroso-N-acetylpenicillamine (SNAP), act on small vessels or peripheral vascular beds primarily through the activation of guanylate cyclase, they act on larger vessels by activating potassium ion channels leading to cell hyperpolarization. Our findings may also be explained by the fact that the inhibition of phosphodiesterase by caffeine in the LLNO1 structure increases the relaxation effect of NO donors. This would also account for the smaller effect of LLNO1 on large vessels, in comparison to FONO1, where caffeine is known to be vasoconstrictive. The study did not investigate alternative mechanisms, such as ion channel blockers, involved in tissue relaxation.

It has been demonstrated that oxyhemoglobin reduces the effect of substances of the nitrosyl-ruthenium complex upon rat hippocampus (7). The present study shows that the presence of oxyhemoglobin does not neutralize but reduces the relaxation effect dosedependently. In other words, even in the presence of an extracellular scavenger, LLNO1 and FONO1 are still capable of inducing vasodilation by releasing intracellular NO.

Similar findings were reported by Figueredo et al. (13) in a study demonstrating that oxyhemoglobin reduces but does not completely neutralize the relaxation effect of SNP upon the vascular endothelium. This is supported by the findings of Bonaventura, et al. 
who showed that oxyhemoglobin reduces the potency but not the maximum effect of substances of the nitrosyl-ruthenium complex upon rat aortic rings (9).

Studies by McDonald and Murad show that NO acts by activating soluble guanylate cyclase and thereby increasing the synthesis and availability of intracellular cGMP (14). When the authors incubated tissues with high doses of soluble guanylate cyclase-specific inhibitor (ODQ; $100 \mu \mathrm{M}$ ), the relaxation response induced by LLNO1 or FONO1 was completely neutralized, thus evidencing the participation of those substances in the NO/cGMP intracellular signaling mechanism. One of the flaws of our study was to have used doses of ODQ high enough to interfere with NO donation, as demonstrated by Feelisch and colleagues (15).

Bonaventura, et al. have shown that compounds of the nitrosyl-ruthenium complex act by donating free nitric oxide (NO) and nitrosyl anions $\left(\mathrm{NO}^{-}\right)$. However, the addition of the nitrosyl anionspecific scavenger L-cysteine did not reduce the relaxation effect produced by those compounds. It may thus be concluded that LLNO1 and FONO1, although they both pertain to the nitrosyl-ruthenium complex, do not trigger the release of nitrosyl anions when inducing relaxation. On-going studies are expected to identify which NO derivative is involved in LLNO1 and FONO1-induced relaxation.

Our results allow us to conclude that LLNO1 and FONO1 are potent vasodilators acting through different mechanisms capable of releasing intracellular $\mathrm{NO}$ and activating guanylate cyclase. Further studies are being carried out in order to evaluate the action of LLNO1 and FONO1 upon ATP-dependent potassium ion channels and calcium-activated medium and highconductivity potassium ion channels and to quantify cAMP and cGMP dosages.

\section{CONFLICT OF INTEREST}

None declared.

\section{REFERENCES}

1. Andersson KE: Pharmacology of penile erection. Pharmacol Rev. 2001; 53: 417-50.
2. Bush PA, Aronson WJ, Buga GM, Rajfer J, Ignarro LJ: Nitric oxide is a potent relaxant of human and rabbit corpus cavernosum. J Urol. 1992; 147: 1650-5.

3. Palmer RM, Ferrige AG, Moncada S: Nitric oxide release accounts for the biological activity of endothelium-derived relaxing factor. Nature. 1987; 327: 524-6.

4. Lohse MJ, Förstermann U, Schmidt HH: Pharmacology of NO:cGMP signal transduction. Naunyn Schmiedebergs Arch Pharmacol. 1998; 358: 111-2.

5. Bates JN, Baker MT, Guerra R Jr, Harrison DG: Nitric oxide generation from nitroprusside by vascular tissue. Evidence that reduction of the nitroprusside anion and cyanide loss are required. Biochem Pharmacol. 1991; (42 Suppl): S157-65.

6. Seidler M, Uckert S, Waldkirch E, Stief CG, Oelke $\mathrm{M}$, Tsikas D, et al.: In vitro effects of a novel class of nitric oxide (NO) donating compounds on isolated human erectile tissue. Eur Urol. 2002; 42: 523-8.

7. Wieraszko A, Clarke MJ, Lang DR, Lopes LG, Franco DW: The influence of NO-containing ruthenium complexes on mouse hippocampal evoked potentials in vitro. Life Sci. 2001; 68: 1535-44.

8. Lopes GF, Wieraszko A, El-Sherif Y, Clarke MJ: Trans-Labilization of Nitric Oxide in RuII complexes by C-bound imidazoles. Inorg-Chim Acta. 2001; 312: 15-22.

9. Bonaventura D, de Lima RG, Vercesi JA, da Silva RS, Bendhack LM: Comparison of the mechanisms underlying the relaxation induced by two nitric oxide donors: sodium nitroprusside and a new ruthenium complex. Vascul Pharmacol. 2007; 46: 215-22.

10. Feldman HA, Goldstein I, Hatzichristou DG, Krane RJ, McKinlay JB: Impotence and its medical and psychosocial correlates: results of the Massachusetts Male Aging Study. J Urol. 1994; 151: 54-61.

11. Rendell MS, Rajfer J, Wicker PA, Smith MD: Sildenafil for treatment of erectile dysfunction in men with diabetes: a randomized controlled trial. Sildenafil Diabetes Study Group. JAMA. 1999; 281: 421-6.

12. Sathishkumar K, Ross RG, Bawankule DU, Sardar KK, Prakash VR, Mishra SK: Segmental heterogeneity in the mechanism of sodium nitroprusside-induced relaxation in ovine pulmonary artery. J Cardiovasc Pharmacol. 2005; 45: 491-8.

13. de Figueiredo LF, Nelson SH, Mathru M, e Silva MR, Kramer GC: Effects of hemoglobin-based blood substitutes on vasoactivity of rat aortic rings. Artif Organs. 2001; 25: 928-33.

14. McDonald LJ, Murad F: Nitric oxide and cGMP signaling. Adv Pharmacol. 1995; 34: 263-75. 
15. Feelisch M, Kotsonis P, Siebe J, Clement B, Schmidt $\mathrm{HH}$ : The soluble guanylyl cyclase inhibitor $1 \mathrm{H}-$ $[1,2,4]$ oxadiazolo[ $[4,3,-a]$ quinoxalin-1-one is a nonselective heme protein inhibitor of nitric oxide synthase

\section{Correspondence address:}

Dr. João Batista Gadelha de Cerqueira

Rua Paula Ney 599, Apto 302

Fortaleza, Ceará, 60140-200, Brazil

E-mail: joaogadelhac@bol.com.br

\section{EDITORIAL COMMENT}

Worldwide only $50 \%$ of Viagra prescriptions are repeated. On the same hand, the drop-out rate of self-injection therapy varies from $40 \%$ to $70 \%$. It means that we just do not have a therapy for erectile dysfunction that is totally accepted by most patients.

Despite already very well studied the NO donors continue to be a important topic of erectile dysfunction. The current study is very important as a practice of research and a resource of knowledge. and other cytochrome P-450 enzymes involved in nitric oxide donor bioactivation. Mol Pharmacol. 1999; 56: 243-53.
Accepted after revision:

July 10, 2008
Furthermore, a new NO donor molecule that produces erection may also mean a new way of releasing nitric oxide. Otherwise, NO donors have been exhaustively studied in the last three decades without any practical results. In this way, maybe one should pay much attention on the research of new molecules but NO donors that could produce erection and play a clinical role in its therapy.

Dr. Joaquim A. Claro University of Sao Paulo

Sao Paulo, Brazil

E-mail: joaquimclaro@hotmail.com

\section{EDITORIAL COMMENT}

In clinical practice when treating patients with erectile dysfunction (ED) it seems that the use of phosphodiesterase type 5 inhibitors (PDE-5-i) have an efficacy of less than $70 \%$. This is lower than what was proposed by and expected from the phase
III studies of the different PDE-5-I compounds. This is probably due to severe deficiency of endogenous nitric oxide (NO) in the endothelium, which appears in many patients with ED, but also with metabolic syndrome and related co-morbidities 


\section{New NO-Donor Substances of the Nitrosyl-Ruthenium Complex}

such as long term diabetes and arterial hypertension.

Since the publications about NO in Nature in 1987 and the description in the New England Journal of Medicine in 1992 that NO is a mediator of relaxation of the corpus cavernosum in response to neurotransmission, intensive experimental work was done to explore the mechanism of action of $\mathrm{NO}$ and the clinical applications.

Finding a drug which will be capable of increasing the availability of $\mathrm{NO}$ could be an alternative therapeutic approach in the case of treatment failure with the available PDE-5-inhibitors.

NO donors are substances which release or lead to the release of NO. They are possible relaxants of corpus cavernosum and cause vasodilatation. Sodium nitroprusside (SNP) is a NO donor with a strong vasodilatation property, but it can not be used for treatment of ED due to its instable properties and some times the release of toxic components like cyanide.

In this study the authors aim to test in vitro the effect of two NO donor's substances (FONO1 and LLNO1) of the Ruthenium complex on the relaxation of smooth muscle of the corpora and vascular endothelium. In the medical literature there are only 41 studies concerning the use of Nitrosyl Ruthenium complex. Only one of the studies deals with the effect of the complex on the endothelium. This study is the first to test these two substances effect on the corpus cavernosum smooth muscle as previous studies were only performed using the vessels endothelium. The authors also try to evaluate the relaxation mechanism involved. A comparison was made with SNP.
The study presents a clear description of the experiments done but the action mechanism of the substances FONO1 and LLNO1 should be studied in vivo and in vitro in the near future. Both substances are associated with great endogenous $\mathrm{NO}$ availability and LLNO1 induced significant level of relaxation in the corpus cavernosum sample. I expect that in the near future these studies will contribute to the development of a new therapeutic approach on ED.

\section{REFERENCES}

1. Palmer RM, Ferrige AG, Moncada S: Nitric oxide release accounts for the biological activity of endothelium-derived relaxing factor. Nature. 1987; 327: 524-6.

2. Bush PA, Aronson WJ, Buga GM, Rajfer J, Ignarro LJ: Nitric oxide is a potent relaxant of human and rabbit corpus cavernosum. J Urol. 1992; 147: 1650-5.

3. Masuda H, Tsujii T, Okuno T, Kihara K, Goto M, Azuma H: Accumulated endogenous NOS inhibitors, decreased NOS activity, and impaired cavernosal relaxation with ischemia. Am J Physiol Regul Integr Comp Physiol. 2002; 282: R1730-8.

4. Rajfer J, Aronson WJ, Bush PA, Dorey FJ, Ignarro LJ: Nitric oxide as a mediator of relaxation of the corpus cavernosum in response to nonadrenergic, noncholinergic neurotransmission. N Engl J Med. 1992; 326: 90-4.

5. Gur S, Kadowitz PJ, Trost L, Hellstrom WJ: Optimizing nitric oxide production by time dependent L-arginine administration in isolated human corpus cavernosum. J Urol. 2007; 178: 1543-8.

\author{
Dr. Y. Reisman \\ Urologist, Men's Health Clinic \\ Amstelland Hospital \\ 1186 AM Amstelveen, The Netherlands \\ E-mail:c.reisman@planet.nl
}

